reverse effect. Acidosis, which can be produced clinically by the administration of ammonium chloride, also favours the release of lead from the skeleton.

Recently absorbed lead is said to be stored in the bony trabeculae and, in time, it is deposited in the cortex of the bones as the less soluble tertiary phosphate (Gant, $1938 a, b)$. Such could account for the two different ways in which lead appears to exist in the skeleton.

The question naturally arises as to whether the lead of the skeleton, particularly that laid down under 'normal' conditions, can be mobilized as the result of disease. This applies particularly to those diseases having a gross effect on the skeleton. Brown (1946) and Tompsett (1948) have shown that mobilization of lead, as indicated by an increase in the lead in the blood, can occur in the following conditions: ( $\mathrm{I}$ ) involvement of the skeleton by malignant disease; (2) senile osteoporosis; (3) marrow hyperplasiapernicious anaemia, leukaemia. In such persons, with no history of abnormal exposure to lead, there were no definite clinical symptoms of lead poisoning. In one group, the urinary coproporphyrin levels were determined. These levels are usually elevated in lead poisoning, but were found to be within normal limits in these special cases. The probability is that, in most cases, the release of lead from the skeleton, as the result of the above disease processes, is comparatively slow. In persons with a history of abnormal exposure to lead, the result of such diseases may however be more serious. A case of subacute lymphatic leukaemia, with a history of abnormal exposure to lead, has been reported in which symptoms of lead poisoning appear to have been precipitated by the disease (Brown \& Tompsett, 1945).

\title{
REFERENCES
}

Aub, J. C., Minot, A. S., Fairhall L. T. \& Reznikoff, P. (1926). Lead Poisoning. Baltimore: Williams and Wilkins Co.

Brown, A. (1946). Quart. F. Med. 57, 77.

Brown, A. \& Tompsett, S. L. (1945). Brit. med. F. ii, 764.

Gant, V. A. (1938a). Industr. Med. 7, 608.

Gant, V. A. (1938b). Industr. Med. 7, 679 .

Lynch, G. R., Slater, R. H. \& Osler, T. G. (1934). Analyst, 59, 787.

Murray, M. M. \& Wilson, D. C. (1946). Lancet, 251, 821.

Tompsett, S. L. (1936). Biochem. F. 30, 345.

Tompsett, S. L. (1948). Unpublished data.

Tompsett, S. L. \& Anderson, A. B. (1935). Biochem. F. 29, 1851 .

\section{Radiology of Bones in Health and Disease}

By R. McWhirTer, Department of Radiology, Royal Infirmary, Edinburgh

Text not received for publication. 